
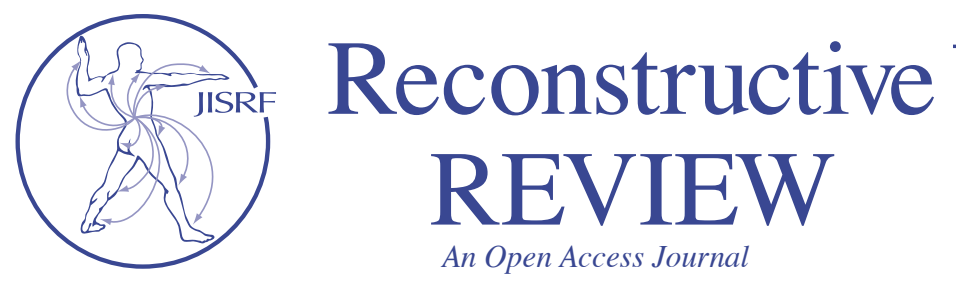

Check for updates

\title{
Risk Factors for Blood Transfusion After Primary Total Hip Arthroplasty
}

Kesler K ${ }^{1}$, Brown $T^{1}$, Martin $J^{2}{ }^{2}$, Springer $B D^{2}$, Otero $J E^{1}$

\begin{abstract}
Background: In the setting of rising healthcare costs, more cost efficiency in total hip arthroplasty (THA) is required. Following THA, most patients are monitored with serial hemoglobin/hematocrit $(\mathrm{H} / \mathrm{H})$ testing despite few needing blood transfusions. This testing adds cost and may not be necessary in most patients. This study aims to identify factors associated with transfusion, therefore guiding $\mathrm{H} / \mathrm{H}$ monitoring following THA.
\end{abstract}

Patients and Methods: Patients who underwent primary THA in 2015 were identified using the National Surgical Quality Improvement Project (NSQIP) database. Patients discharged on the day of surgery were excluded. Patients were classified into those receiving transfusion versus no transfusion. Demographics and comorbidities were compared between groups followed by univariate and multivariate analysis, allowing identification of patient characteristics and comorbidities associated with transfusion.

Results: Overall, 28664 patients who underwent THA patients were identified. Within this group, 6.1\% $(n=1737)$ had a post-operative transfusion. Patients receiving a blood transfusion were older, had lower body mass index, and had higher rates of chronic obstructive pulmonary disease (COPD), heart failure, dialysis, prior transfusion, and were more frequently ASA class 3-4 ( $<<0.001)$. Univariate analysis demonstrated that patients requiring transfusion had higher complication rates (4.3\% vs. $12.8 \%, \mathrm{p}<0.0001)$. Multivariate analysis identified age $>70$, diabetes, smoking, COPD, prior transfusion, and operative time $>2$ hours as independent risk factors for transfusion.
Conclusion: Among THA patients, characteristics and comorbidities exist that are associated with increased likelihood of transfusion. Presence of these factors should guide $\mathrm{H} / \mathrm{H}$ monitoring post-operatively. Selective $\mathrm{H} / \mathrm{H}$ monitoring can potentially decrease the cost of THA.

\section{Background}

As the procedure improves and the population ages, the demand for and frequency of primary total hip arthroplasty (THA) continues to increase within the United States. The demand for primary THA is projected to grow by $174 \%$ to 572,000 cases annually in 2030 in the United States. [1] In the current climate of increasing healthcare costs, this raises the importance of efficiency and cost-effectiveness in THA. Laboratory testing is the single highest volume medical activity and a significant factor in inpatient cost. [2] Reflex daily phlebotomy has been shown to be a significant contributor to cost and multiple strategies are being implemented to reduce its frequency throughout inpatient stays. [준 $\underline{\text { ] }}$ Daily postoperative hemoglobin/hematocrit $(\mathrm{H} / \mathrm{H})$ monitoring in THA is commonplace. However, if appropriately screened preoperatively, only a minority of patients actually progress to thresholds that require an allogenic blood transfusion. [5-7] Costs vary by institution with a recent study quoting $\$ 2800$ as the cost for postop-

Keywords: joint replacement; hip arthroplasty; blood transfusion; hemoglobin testing; hematocrit testing; phlebotomy

Level of Evidence: III (Case control study) 
erative day one $\mathrm{H} / \mathrm{H}$ testing per 100 joint replacement patients compared to $\$ 4000$ at the authors institution. [] Extrapolated across the entire United States joint replacement practice, there is significant opportunity to improve the cost of THA.

In effort to contain cost in THA while maintaining patient safety, thoughtful utilization of postoperative laboratory monitoring is an important modifiable variable. To date, multiple studies have investigated and proposed strategies for minimizing blood transfusion following THA. $[\underline{6}, \underline{8}, \underline{9}]$ It has been mentioned in the literature that hemoglobin testing is likely over utilized, however, data regarding when postoperative hemoglobin testing is necessary is lacking. [ $[$ ] The hypothesis of this retrospective case-control study is that objective factors associated with transfusion exist and could be used to guide more selective and cost effective postoperative $\mathrm{H} / \mathrm{H}$ monitoring in THA.

\section{Patients and Methods}

\section{Data Collection and Patient Selection}

With institutional review board approval, a large database retrospective analysis was performed. The American College of Surgeons National Surgical Quality Improvement Program (NSQIP) database was used to identify patients who underwent THA in 2015 using the primary current procedural terminology code for THA (27130). In an effort to isolate data regarding allogenic (donor) blood transfusions, those patients who discharged on the day of surgery were excluded from analysis as any day of surgery discharge transfusions would primarily represent autogenic transfusions collected, for example, in a Cell Saver System during surgery (Haemonetics Corp., Braintree, MA). This resulted in a final cohort of 28664 patient records available for analysis.

\section{Variables}

Patient demographic factors such as age, gender, race, body mass index, and functional status were easily assessable within the database. [For complete list, refer to Table I] In addition, data on patient comorbidities, pre-operative, and operative variables were collected from the database. These variables were characterized with respect to whether a patient did or did not receive a blood transfusion postoperatively and analyzed accordingly. [Table II]

\section{Outcomes}

The primary outcome examined between groups was whether patients received a blood transfusion post-operatively during the patient's hospital stay. As a means to build a multivariate model, the occurrence of post-operative complications in both the transfused and non-transfused groups was also addressed.

\section{Statistics}

Each patient's demographic factors, health factors, or comorbidities were compared using a univariate analysis with a p-value of less than 0.05 representing significance. Continuous variables were compared using a two-tailed student t-test whereas categorical variables were compared using a chi-squared test. In addition, this large dataset provided the ability to create a logistic regression model to analyze the data in a multivariate manner. The multivariate analysis was created using independent variables from the univariate comparison with p-values less than 0.1 . This allowed calculation of odds ratios based on the factors included and was expressed as a ratio with a $95 \%$ confidence interval. [Table III]

\section{Results}

In total from the database, 28,664 patients were identified who met study criteria. Within this group, $6.1 \%$ $(n=1737)$ received an allogenic blood transfusion postoperatively. In the transfusion group, patients were significantly older (64.5 vs. 67.3 years, $\mathrm{p}<0.001)$, more likely to be female $(53.8 \%$ vs. $68.7 \%, \mathrm{p}<0.001)$, had a lower body mass index $(24.4 \mathrm{vs} .21 .1 \mathrm{~kg} / \mathrm{m} 2, \mathrm{p}<0.001)$ and were more frequently ASA class $3-4$ (41.9\% vs. $58.5 \%$, p<0.001). Of note, the groups were not significantly different with regard to race or recent weight loss. [Table I]

Furthermore, univariate analysis of the groups demonstrated that patients in the transfusion group were significantly more likely to have COPD, congestive heart failure (CHF), dialysis, prior steroid use, history of bleeding disorder, and history of previous blood transfusion. With respect to pre-operative laboratory values, hematocrit, creatinine, serum albumin, and INR were all statistically worse in the transfusion group. The transfusion group was more likely to have a longer operation. [Table I]

There were statistically significant differences between the groups regarding post-operative complications with patients who received transfusions having higher rates of overall complications (12.78\% versus $4.28 \%$ respectively, $\mathrm{p}<0.001)$. Despite the overall high rate of complications, there were not statistically higher rates of wound dehiscence, deep vein thrombosis, pulmonary embolism, or stroke. All other measured complications where higher in the transfusion group. [Table II]

Multivariate logistic regression analysis revealed inde- 
Table I. Demographics, Comorbidities, Pre-operative, and Operative Variables

\begin{tabular}{|c|c|c|c|}
\hline & No Transfusion $(\mathrm{n}=\mathbf{2 6 9 2 7})$ & Transfusion $(n=1737)$ & p-value \\
\hline \multicolumn{4}{|l|}{ Demographics } \\
\hline Age, mean (SD) & $64.54(11.52)$ & $67.25(13.87)$ & $<0.0001$ \\
\hline Female gender $(\%)$ & 53.76 & 68.74 & $<0.0001$ \\
\hline Race/ethnicity (\%) & & & 0.0006 \\
\hline White & 88.62 & 85.60 & \\
\hline Black & 9.08 & 10.94 & \\
\hline Other & 2.30 & 3.45 & \\
\hline BMI (kg/m2), mean (SD) & $24.38(9.19)$ & $21.70(9.14)$ & $<0.0001$ \\
\hline Recent weight loss $(\%)$ & 0.17 & 0.40 & 0.0252 \\
\hline ASA class $(\%)$ & & & $<0.0001$ \\
\hline 1 - No Disturbance & 4.04 & 1.50 & \\
\hline 2 - Mild Disturbance & 54.06 & 40.01 & \\
\hline 3 - Severe Disturbance & 40.32 & 54.17 & \\
\hline 4- Life Threatening Disturbance/5-Moribund & 1.58 & 4.32 & \\
\hline Functional Status (\%) & & & $<0.0001$ \\
\hline Independent & 98.22 & 94.22 & \\
\hline Dependent & 1.78 & 5.78 & \\
\hline \multicolumn{4}{|l|}{ Pre-operative health and comorbidities } \\
\hline Diabetes mellitus $(\%)$ & 11.53 & 13.82 & 0.0040 \\
\hline Smoking $(\%)$ & 13.90 & 11.28 & 0.0021 \\
\hline Chronic obstructive pulmonary disease $(\%)$ & 3.88 & 6.10 & $<0.0001$ \\
\hline Congestive heart failure $(\mathrm{CHF})(\%)$ & 0.27 & 0.81 & $<0.0001$ \\
\hline Dialysis $(\%)$ & 0.21 & 0.86 & $<0.0001$ \\
\hline Steroids (\%) & 3.65 & 5.76 & $<0.0001$ \\
\hline Bleeding disorder $(\%)$ & 1.88 & 5.53 & $<0.0001$ \\
\hline Pre-op blood transfusion $(\%)$ & 0.05 & 0.86 & $<0.0001$ \\
\hline Open wound or wound infection (\%) & 0.30 & 0.86 & $<0.0001$ \\
\hline Pre-op Sepsis $(\%)$ & 0.17 & 0.40 & 0.0290 \\
\hline \multicolumn{4}{|l|}{ Pre-operative laboratory values } \\
\hline WBC, Mean (SD) & $7.11(2.74)$ & $7.01(2.69)$ & 0.1478 \\
\hline Hematocrit, Mean (SD) & $41.45(3.97)$ & $37.43(4.87)$ & $<0.0001$ \\
\hline Platelets, Mean (SD) & $248.7(65.55)$ & $251.7(84.50)$ & 0.1560 \\
\hline Creatinine, Mean (SD) & $0.91(0.42)$ & $1.00(0.81)$ & $<0.0001$ \\
\hline Serum Albumin, Mean (SD) & $4.14(0.39)$ & $4.00(0.49)$ & $<0.0001$ \\
\hline INR, Mean (SD) & $1.02(0.22)$ & $1.06(0.34)$ & $<0.0001$ \\
\hline \multicolumn{4}{|l|}{ Operative Variables } \\
\hline Wound class & & & $<0.0001$ \\
\hline Clean & 99.53 & 97.41 & \\
\hline Clean-contaminated & 0.31 & 1.44 & \\
\hline Contaminated & 0.10 & 0.52 & \\
\hline Dirty or infected & 0.07 & 0.63 & \\
\hline \multicolumn{4}{|l|}{ Length of operation, min (SD) } \\
\hline Mean (SD) & $91.62(38.85)$ & $122.0(59.15)$ & $<0.0001$ \\
\hline
\end{tabular}


Table II. Complications

\begin{tabular}{|l|c|c|c|}
\hline Complications (\%) & $\begin{array}{c}\text { No Transfusion } \\
(\mathbf{n = 2 6 9 2 7})\end{array}$ & $\begin{array}{c}\text { Transfusion } \\
(\mathbf{n = 1 7 3 7})\end{array}$ & p-value \\
\hline Any Complication & 4.28 & 12.78 & $<0.0001$ \\
\hline \multicolumn{5}{|l|}{} \\
\hline Superficial Wound Infection & 0.59 & 0.92 & 0.0821 \\
\hline Deep Wound Infection & 0.34 & 0.81 & 0.0020 \\
\hline Organ Space Infection & 0.25 & 0.63 & 0.0029 \\
\hline Wound Dehiscence & 0.16 & 0.23 & 0.5309 \\
\hline Pneumonia & 0.27 & 1.78 & $<0.0001$ \\
\hline Urinary Tract Infection & 0.76 & 2.19 & $<0.0001$ \\
\hline Sepsis & 0.25 & 0.58 & 0.0107 \\
\hline Septic Shock & 0.04 & 0.29 & $<0.0001$ \\
\hline Deep Vein Thrombosis & 0.35 & 0.63 & 0.0531 \\
\hline Pulmonary Embolism & 0.26 & 0.40 & 0.249 \\
\hline Renal Insufficiency & 0.09 & 0.35 & 0.0014 \\
\hline Acute Renal Failure & 0.04 & 0.17 & 0.0402 \\
\hline Stroke & 0.06 & 0.17 & 0.1175 \\
\hline Cardiac Arrest & 0.06 & 0.23 & 0.0299 \\
\hline Myocardial Infarction & 0.17 & 1.15 & $<0.0001$ \\
\hline Unplanned Intubation & 0.13 & 0.40 & 0.0039 \\
\hline Unplanned Re-admission & 3.17 & 7.94 & $<0.0001$ \\
\hline Re-operation & $59(2.12)$ & $4.07(3.88)$ & $<0.0001$ \\
\hline Mortality & & & $<0.0001$ \\
\hline Length of hospital stay (days) & \multicolumn{3}{|l|}{} \\
\hline
\end{tabular}

pendent factors associated with increased transfusion rates including age greater than 70 years, non-independent functional status, ASA class 3 or greater, diabetes, smoking, COPD, pre-operative steroid use, previous transfusion, and operative time greater than 2 hours. Despite significance in univariate analysis, congestive heart failure, dialysis, and a history of a bleeding disorder did not prove to be independently associated with post-operative blood transfusion. [Table III]

\section{Discussion}

Healthcare spending continues to increase and with this increase surgeons, patients, and payers are more interested in controlling cost across hospitals. The cost of laboratory testing has already been recognized as an important area for improvement relating to economical spending. [2-4] Multiple studies, including this study, have demonstrated that allogenic blood transfusions occur at nontrivial rates following THA.[ㅍ-9] These studies addressed frequency
Table III. Multivariable logistic regression for the probability of blood transfusion

\begin{tabular}{|l|c|c|}
\hline & $\begin{array}{c}\text { Odds } \\
\text { Radio }\end{array}$ & $\begin{array}{c}\mathbf{9 5 \%} \text { Confidence } \\
\text { Interval }\end{array}$ \\
\hline Age 50-60 versus <50 & 0.96 & $0.74-1.25$ \\
\hline Age 60-70 versus <50 & $\mathbf{0 . 9 5}$ & $\mathbf{0 . 7 4}-\mathbf{1 . 2 3}$ \\
\hline Age 70-80 versus <50 & $\mathbf{1 . 3 6}$ & $\mathbf{1 . 0 5}-\mathbf{1 . 7 7}$ \\
\hline Age >80 versus <50 & 1.48 & $1.11-1.98$ \\
\hline Female Gender & 1.11 & $0.98-1.26$ \\
\hline Race & 0.93 & $0.61-1.40$ \\
\hline $\begin{array}{l}\text { Non-independent } \\
\text { functional status }\end{array}$ & $\mathbf{1 . 5 1}$ & $\mathbf{1 . 1 0}-\mathbf{2 . 0 6}$ \\
\hline ASA class (\%) & 1.25 & $0.76-2.05$ \\
\hline 2 - Mild Disturbance & $\mathbf{2 . 1}$ & $\mathbf{1 . 2 8}-\mathbf{3 . 4 6}$ \\
\hline 3 - Severe Disturbance & $\mathbf{3 . 6}$ & $\mathbf{1 . 9 9}-\mathbf{6 . 3 8}$ \\
\hline $\begin{array}{l}\text { 4- Life Threatening } \\
\text { Disturbance/5-Moribund }\end{array}$ & $\mathbf{1 . 2}$ & $\mathbf{1 . 0 1}-\mathbf{1 . 4 3}$ \\
\hline Diabetes mellitus & $\mathbf{1 . 2 1}$ & $\mathbf{1 . 0 1}-\mathbf{1 . 4 5}$ \\
\hline Smoking (\%) & $\mathbf{1 . 3 3}$ & $\mathbf{1 . 0 4}-\mathbf{1 . 7 0}$ \\
\hline $\begin{array}{l}\text { Chronic obstructive } \\
\text { pulmonary disease }(\%)\end{array}$ & 1.31 & $0.65-2.68$ \\
\hline $\begin{array}{l}\text { Congestive heart failure } \\
\text { (CHF)(\%) }\end{array}$ & 1.03 & $0.43-2.43$ \\
\hline Dialysis (\%) & $\mathbf{1 . 4 8}$ & $\mathbf{1 . 1 4}-\mathbf{1 . 9 1}$ \\
\hline Steroids (\%) & 1.06 & $0.76-1.48$ \\
\hline Bleeding disorder (\%) & $\mathbf{3 . 4 6}$ & $\mathbf{1 . 3 3}-\mathbf{9 . 0 2}$ \\
\hline $\begin{array}{l}\text { Pre-op blood transfusion } \\
\text { (\%) }\end{array}$ & $\mathbf{1 . 2 4}$ & $\mathbf{1 . 0 7}-\mathbf{1 . 4 3}$ \\
\hline Operative Time >2 hours & & \\
\hline
\end{tabular}

of transfusion as well as strategies for minimizing rates of transfusion; however, the avoidance of reflex $\mathrm{H} / \mathrm{H}$ testing was not addressed in prior studies. In this cohort, the $6.1 \%$ $(n=1737)$ of patients who received allogenic blood transfusions represent a minority of the over 28,000 patient analyzed, many of whom underwent serial $\mathrm{H} / \mathrm{H}$ testing.

It was our belief that associated factors exist that would be able to guide more appropriate $\mathrm{H} / \mathrm{H}$ testing in patients following THA. This study sought to isolate patients who under went THA and evaluate if such statistically significant factors exist. Our results indicate that those patients at the highest risk requiring a transfusion tended to be older and had lower body mass indices in addition to having higher ASA classes. Pre-operative laboratory values including hematocrit, creatinine, serum albumin, and INR were all statistically worse in the transfusion group, however, the differences between the two groups regarding laboratory values were thought to be below clinical sig- 
nificance and not included in multivariate analysis. [Table I] Comorbidities including diabetes, COPD, and smoking proved to be a significant in the multivariate analysis and demonstrate that these represent independent risk factors.

Further study will likely be needed prior to the development of specific guidelines for $\mathrm{H} / \mathrm{H}$ testing after THA, however, it is our recommendation from the findings in this study that surgeons critically evaluate whether is $\mathrm{H} / \mathrm{H}$ testing is necessary for all patients. Specifically, non-smoking patients under 70 years old without a history of steroid use or previous transfusion who are independent at baseline and do not carry a diagnosis of COPD or diabetes deserve extra consideration regarding the necessity of daily reflex $\mathrm{H} / \mathrm{H}$ testing.

This study is not without imitations. As in all database studies, the findings in this study rely on accurate coding and documentation including that of comorbidities and transfusion events in the electronic medical record. Tranexamic acid (TXA) administration likely plays a role in rates of transfusion following THA. TXA use, dosing, and timing varies widely between practices and was not evaluated as part of this study. As TXA use increases and potentially standardizes it may serve as another factor influencing decisions regarding $\mathrm{H} / \mathrm{H}$ testing. In addition, there is some ambiguity relating to the transfusion $\mathrm{H} / \mathrm{H}$ threshold used by various surgeons. It is a necessary assumption that most surgeons would be following generally accepted transfusion guidelines and we do not believe this assumption affects the generalizability or validity of this study.

In a large cohort of patients who underwent THA, independent demographic characteristics, operative factors, and comorbidities exist that are statistically associated with an increased likelihood of transfusion. Given these findings, it is recommended that surgeons critically evaluate the necessity and utility of reflex daily $\mathrm{H} / \mathrm{H}$ in those patients that are the least likely to meet transfusions thresholds. Further studies regarding specific guidelines for $\mathrm{H} / \mathrm{H}$ testing should be conducted and ultimately may result in more efficient healthcare resource utilization.

\section{References}

1. Kurtz, S., et al., Projections of primary and revision hip and knee arthroplasty in the United States from 2005 to 2030. JBJS, 2007. 89(4): p. 780-785.

2. Zhi, M., et al., The landscape of inappropriate laboratory testing: a 15 -year metaanalysis. PloS one, 2013. 8(11): p. e78962.

3. Stuebing, E.A. and T.J. Miner, Surgical vampires and rising health care expenditure: reducing the cost of daily phlebotomy. Archives of Surgery, 2011. 146(5): p. 524-527.

4. May, T.A., et al., Reducing unnecessary inpatient laboratory testing in a teaching hospital. American journal of clinical pathology, 2006. 126(2): p. 200-206.

5. Hart, A., et al., Blood transfusion in primary total hip and knee arthroplasty. Incidence, risk factors, and thirty-day complication rates. JBJS, 2014. 96(23): p. 1945-1951.

6. Holt, J.B., et al., Minimizing blood transfusion in total hip and knee arthroplasty through a multimodal approach. The Journal of arthroplasty, 2016. 31(2): p. 378382.

7. Bedard, N.A., et al., Recent trends in blood utilization after primary hip and knee arthroplasty. The Journal of arthroplasty, 2017. 32(3): p. 724-727.

8. Martin, J.R., et al., Noninvasive Hemoglobin Monitoring: A Rapid, Reliable, and Cost-Effective Method Following Total Joint Replacement. JBJS, 2016. 98(5): p. 349-355.

9. Frew, N., et al., Impact of a blood management protocol on transfusion rates and outcomes following total hip and knee arthroplasty. The Annals of The Royal College of Surgeons of England, 2016. 98(6): p. 380-386.

\section{SUBMISSION HISTORY}

Submitted: May 2, 2019

Reviewed: June 9, 2019

Revised: July 10, 2019

Accepted: June 2, 2019

Published: November 22, 2019

\section{AUTHOR AFFILIATIONS}

1 Kyle K. Kesler, MD; Timothy S. Brown, MD; Jesse Otero, MD, PhD University of lowa Hospital and Clinics, lowa City, IA - USA

2 J. Ryan Martin, MD; Bryan D. Springer, MD OrthoCarolina, Hip and Knee Center, Charlotte, NC - USA

(Direct inquires to Kyle Kesler, kyle-kesler@uiowa.edu)

AUTHOR DISCLOSURES

This research received no specific grant from any funding agency in the public, commercial, or not-for-profit sectors. The Author(s) declare(s) that there is no conflict of interest.

\section{COPYRIGHT \& OPEN ACCESS}

(C) 2019 Kesler, Brown, Martin, Springer, Otero. All rights reserved. Authors retain copyright and grant the journal right of first publication with the work. Reconstructive Review is an open access publication and follows the Creative Commons Attribution-NonCommercial CC BY-NC. This license allows anyone to download works, build upon the material, senior author Reconstructive Review, and the Joint Implant Surgery \& Research Foundation (JISRF). An example credit would be: "Courtesy of (senior author's name), Reconstructive Review, JISRF, Chagrin Falls, Ohio". 